\title{
Drug Prescription Analysis at Hospital Discharge for Heart Failure Patients at the Institute of Cardiology of Abidjan
}

\author{
Djenamba Bamba-Kamagate*, Iklo Coulibaly, Esaïe Soya, Fatoumata Traore, \\ Marie-Paule N'Choh-Mattoh, Florent Koffi, Micesse Tanoh \\ Medicine Department, Institute of Cardiology of Abidjan, Abidjan, Côte D'Ivoire \\ Email: *djeneba.bamba@hotmail.fr
}

Received 4 January 2016; accepted 21 March 2016; published 24 March 2016

Copyright (C) 2016 by authors and Scientific Research Publishing Inc.

This work is licensed under the Creative Commons Attribution International License (CC BY). http://creativecommons.org/licenses/by/4.0/

(c) (i) Open Access

\begin{abstract}
Introduction: Understanding improvement of pathophysiology of heart failure has allowed therapeutic progress over the past two decades in the pathology management. Our patients should benefit from these new drugs that improve survival. Objective: To analyze the treatment of hospital discharge according to ESC (European Society of Cardiology) Guidelines. Methods: We carried out a retrospective and descriptive study which included completed survey of patients hospitalized for heart failure in Medicine Department of cardiology Institut of Abidjan between January 1st 2011 to December 31st 2012. We analyzed the drugs prescription during hospital discharge by using the register of hospitalization. Results: $\mathbf{9 2 . 9 \%}$ of the 532 files retained were included. Patients had a mean age of $54.4 \pm 16.4$ years old. $36.3 \%$ of the cases had a heart failure history with an average of $5.7 \pm 3.2$ days of hospital stay. At the hospital discharge, patients had for prescription: a diuretic specially Furosemide $(100 \%)$, angiotensin converting enzyme inhibitor (ACEI) or angiotensin receptor blockers (ARB) $(63.7 \%)$, a beta-blocker (17.9\%) and a mineralocorticoids receptor antagonist (MRA) (51.2\%). Diuretic, IEC or ARB and the MRA were prescribed systematically. Beta-blockers were lower prescribed to patients who showed no more signs of congestion. Conclusion: Our prescribing practices were adapted to the guidelines for heart failure management. However, the gaps will be corrected through sensitization and training.
\end{abstract}

\section{Keywords}

Heart Failure, Prescription, Hospitalization, Discharge, Beta-Blockers

\footnotetext{
${ }^{*}$ Corresponding author.
}

How to cite this paper: Bamba-Kamagate, D., Coulibaly, I., Soya, E., Traore, F., N'Choh-Mattoh, M.-P., Koffi, F. and Tanoh, M. (2016) Drug Prescription Analysis at Hospital Discharge for Heart Failure Patients at the Institute of Cardiology of Abidjan. World Journal of Cardiovascular Diseases, 6, 73-79. http://dx.doi.org/10.4236/wjcd.2016.63008 


\section{Introduction}

Heart failure is a serious and frequent disease. Its prevalence is increasing in all continents [1]-[4]. It reaches especially the elderly subjects in Western countries [5]. However, in sub-Saharan Africa, it affects young subjects around fifty [4] [6] with high morbidity and mortality in short and long term [6], thus reducing quality of life and productivity in developing countries. During these last two decades, therapeutic progress in the management of heart failure is mainly drugs (ACEI: Angiotensin-Converting Enzyme Inhibitor, ARB: Angiotensin 2 Receptor Blocker and Beta-blocker) that prolong survival [7].

Facing with the strong hospital and post-hospital morbidity, a track of improving the medicine precrisption would be the optimization of therapeutic after hospitalization discharge. However, fewer studies are carried out on the follow-up of the ambulatory medicine use for heart failure in real life. Two recent published studies agree on the benefit of Beta-blocker and ACEI or ARB combination [8] [9]. The first study carried out on the analysis of the therapeutic managment of 1137 heart failure patients at hospital discharge after cardiac decompensation over 18 months according to the ejection fraction, had concluded with an increase of the use of drugs recommended like ACEI or ARB in heart failure, with in particular, associated to beta-blockers. Indeed, majority of the patients (62\%) received combination of beta-blocker and ACEI or ARB, and $56 \%$ of them had reached at least $50 \%$ of the target dose for each treatment [8]. The second study according to De Groote permitted setting up an observational register whose objective was to assess in liberal cardiology, the ambulatory managment of 5465 chronic heart failure patients with systolic dysfonction, between October 2004 and March 2006, according to the recommended guidelines of the European Society of Cardiology (ESC). The prescription analysis of three principal drugs ACEI-ARB-beta-blocker showed an improvement in time of their rate of prescription. The proportion of patients reaching target dose or $50 \%$ of this dose was significant, with a progression amongst patients treated by beta-blocker from $65 \%$ to $78 \%$ [9]. However, an improvement is still possible with regard to the administered doses.

The lack of adequate follow-up and the access difficulties to care in our health facilities, are one of our limits in heart failure management as well as the practitioners' reserve or fear of using beta-blockers in this condition. Heart failure patients of our Department should benefit such type of therapeutic. The objective of this work was to analyze the treatment of patients at hospital discharge, according to ESC (European Society of Cardiology) guidelines, to improve their drug management during their follow-up.

\section{Methods}

Material: We used the register of hospitalization where all the patients admitted to the medical service of the Institute of Cardiology of Abidjan (ICA) are recorded. This register includes the following data: age, sex, admission and discharge date and final diagnosis held with. The patient file allowed to collect on a questionnaire designed for this purpose, the socio-demographic, clinical, echocardiographic, biological and therapeutic data.

Study design: This retrospective and descriptive preliminary study from January 2011 to December 2012 related to the analysis of files of patients admitted for decompensation in the medical service of ICA. Were included in this study, patients above 5 years, irrespective of sex, nor of residence area who were hospitalized for depressive heart failure during the study period. In the selected period, we identified patients in the hospitalization register of medical service, starting by the discharge diagnosis. Then we sought out the files from the archives' service for reading and validation. We retained or selected the completed files. The uncompleted, untraceable ones or patients admitted outside of the above-mentioned period, were excluded. The parameters studied were the following: sociodemographic data (age, sex), clinic (heart failure history, type of heart failure, New York Heart Association stages (NYHA), duration of hospital stay; echocardiographic (underlying heart disease, LVTDD, LVEF, SLAP, mitral profile); biological (Natremia, kalemia, NT-ProBNP, serum creatinine, hemoglobin) and therapeutic data (diuretic, ACEI, ARB, beta-blocker, MRA or Mineralocorticoids Receptor Antagonist, etc.).

The collection of inform form is nonapplicable because it is about a retrospective study of files without direct intervention. However, we have respected the declaration of Helsinki and the anonymity of the data. Also, Ethical approval from national ethics service was not sought as this work was a service evaluation of the therapeutics offered by the ICA.

Data collection and statistical analysis: The lack of local data on prescription of beta-blockers for heart failure patients did not permit to calculate the sample size. So we chose an exhaustive sample from the register 
of hospitalization. The data were keyed in and analyzed on Epi-Info version 3.5. The data were presented in proportion form for the qualitative variables and average with standard deviation for quantitative variables.

\section{Results}

Out of the 532 files retained over the study period, 38 were excluded for various reasons (uncompleted files, non-available, children, in course of hospitalization). The 494 completed ones were included and exploited either $92.9 \%$ of the files selected.

Patients mean age was $54.4 \pm 16.4$ years old with a male predominance (53.1\%). Less than half had a history of acute heart failure (36.4\%). The majority of the patients were admitted for global heart failure (68.3\%). The average systolic blood pressure was $131 \pm 25 \mathrm{mmHg}$. The mean duration of hospital stay was $5.7 \pm 3.2$ days ranging: 01 day and 20 days (Table 1 ).

Echocardiographic data allowed to note an average LVEF of $36 \pm 13 \%$ with LVEF reduction in $87.8 \%$. Underlying heart disease was dominated by cardiomyopathy (64.3\%) followed by ischemic heart disease (13.8\%), valvular heart disease (11.8\%) and hypertensive heart disease (8.6\%). The average SLAP was $53.8 \pm 15.6$ mmHg (Table 1).

Biology exhibited a mean natremia of $133.8 \pm 7.8 \mathrm{mEq} / \mathrm{l}$ with hyponatremia in $40 \%$ of the cases. Hypokalemia was observed in $21.6 \%$ of the cases. The average serum creatinine level was $14.8 \pm 9.6 \mathrm{mEq} / \mathrm{l}$ with kidney function alteration in $6.1 \%$ of the cases. Anemia was seen in $11.4 \%$ of patients (Table 1 ).

The main treatment during hospitalization was based of furosemide (100\%), ACEI or ARB (66.8\%), MRA (63.7\%) and beta-blockers (18.2\%). Other treatment summarized in Table 2, included: Digoxin (72.3\%), Calcium channel blocker (11.7\%), aspirin (12.7\%), amiodaron (19.8\%), preventive and curative anticoagulant dose (93.9\%), nitrate derivatives (11.7\%), statins (12.7\%), clopidogrel (12.7\%). Patients had furosemide, ACEI or ARB and MRA combination in $62 \%$ of the cases. Associating furosemide and MRA were observed in $51.4 \%$ of the cases. Combination beta-blocker, ACEI or ARB accounted for $18.2 \%$ of the cases.

At the hospitalization discharge, patients had a diuretic (100\%), an ACEI or ARB (63.7\%) with optimal dose achieved in $11.9 \%$ of the cases, a weak prescription of beta-blocker (15.6\%) with optimal dose achieved in 3.4\% of the cases and mineralocorticoids receptor antagonist or MRA (25.5\%). Others drugs were often prescribed: Digoxin (44.6\%), aspirin (10.3\%), anticoagulant (16.6\%), amiodaron (23.3\%) and amlodipine (15.6\%). The majority of patients (63.7\%) received diuretic and ACEI or ARB combination. A low proportion (15.6\%) received ACEI or ARB, beta-blockers and MRA combination. The optimal dose was achieved respectively in $11.9 \%$ and 3.4\% for the ACEI or ARB and beta-blockers (Table 2).

According to LVEF, heart failure patients with preserved LVEF had more diuretic (12.2\%) and ACEI or ARB (12.2\%) but fewer beta-blockers (1.9\%). Beta-blockers were under-prescribed in both groups (reduced LVEF and preserved LVEF) respectively in $13.7 \%$ and $1.9 \%$ of the cases. Under prescription of beta-blockers was associated with some factors: lack of completed clinical stabilization state (9.1\%), low systolic blood pressure (15\%), LVEF > 40\% (21.7\%), and Digoxin use (44.6\%).

\section{Discussion}

Main drugs (diuretics, ACEI or ARB, beta-blockers and MRA) used in heart failure were prescribed in this study. Diuretics were prescribed to all patients. Indeed, the diuretics provide the basis for the management of congestive heart failure. In addition, patients were almost all in global heart failure. This major congestion state could explain this massive diuretic prescription (87\% of the cases) at hospitalization discharge. This result is similar to that of Cohen-Solal [8] who found diuretic prescription in $87 \%$ of cases at hospitalization discharge in France. The majority of these patients were admitted at NYHA class II-III.

After hospitalization, patients had also received ACEI or ARB in significant proportion according to the LVEF that is less than $40 \%$ as recommended by the Guidelines [7]. But few of them had reached the optimal dose. This is due to the fact that blood pressure did not permit to reach optimal doses. In addition, kidney dysfunction in some patients motivated precaution in prescribing ACEI or ARB, which could affect kidney function [10]. Usually, this renal action was clinically non significant that does not justify stopping the treatment. So ACEI or ARB may be prescribed in heart failure patients with kidney failure with care [11]. They will be stopped in case of sudden drop in the glomerular filtration rate. Moreover, prescription of ACEI or ARB after hospitalization is a predictive factor of compliance or observance [12] [13]. This observance at discharge is 
Table 1. Demographic, clinical, echocardiographic and biological characteristics.

\begin{tabular}{|c|c|c|}
\hline Patient characteristics & $N=494$ & $\%$ \\
\hline \multicolumn{3}{|l|}{ Demographics } \\
\hline \multicolumn{3}{|l|}{ Age (Years) } \\
\hline Sexe (Men) & 262 & 53.1 \\
\hline \multicolumn{3}{|l|}{ Sex ratio } \\
\hline \multicolumn{3}{|l|}{ Clinic } \\
\hline Heart failure history & 179 & 36.3 \\
\hline \multicolumn{3}{|l|}{ Weight (Kg) } \\
\hline \multicolumn{3}{|l|}{ Admission } \\
\hline \multicolumn{3}{|l|}{ Outgoing } \\
\hline \multicolumn{3}{|c|}{ Type of Heart failure at admission } \\
\hline Acute pulmonary edema & 20 & 4 \\
\hline Left Heart failure & 36 & 7.3 \\
\hline Rigth Heart failure & 28 & 5.7 \\
\hline Global Heart failure & 337 & 68.2 \\
\hline Cardiogenic shock & 13 & 2.6 \\
\hline
\end{tabular}

\section{Echocardiography}

Underlying Heart deseases

$\begin{array}{lcc}\text { Cardiomyopathies } & 313 & 63.4 \\ \text { Ischemic Heart desease } & 63 & 12.7 \\ \text { Valvular Heart desease } & 53 & 10.7 \\ \text { Hypertensive Heart desease } & 38 & 7.7 \\ \text { Others } & 27 & 5.5 \\ \text { Pulmonary hypertension } & 19 & 3.8 \\ \text { Pericarditis in adiastolie } & 7 & 1.4 \\ \text { Myocardite } & 2 & 0.4\end{array}$

LVEF (\%)

\section{LVTDD (mm)}

SLBP (mmHg)

\section{Outgoing biology}

$$
\begin{aligned}
& \text { Hyponatremia (mEq/l) } \\
& \text { Hypokaliemia (mEq/l) } \\
& \text { Reduction of kidney function (>3 mg/l) } \\
& \text { Anemia }(\mathrm{M}<13 \mathrm{~g} / \mathrm{l} ; \mathrm{F}<12 \mathrm{~g} / \mathrm{l})
\end{aligned}
$$


Table 2. Treatment during hospitalization and at discharge.

\begin{tabular}{|c|c|c|c|}
\hline \multirow[t]{2}{*}{ Traetment } & \multirow{2}{*}{$\begin{array}{c}\text { During Hospitalization } \\
\text { N (\%) }\end{array}$} & \multicolumn{2}{|c|}{ At discharge } \\
\hline & & N (\%) & LVEF $\leq 40 \%$ \\
\hline Furosemide & $494(100)$ & 494 (494) & 434 (87.8\%) \\
\hline ACEI or ARB & $182(36.8)$ & 315 (63.7) & 255 (50.9) \\
\hline Target dose & $68(13.8)$ & 59 (11.9) & $22(4.4)$ \\
\hline Betablocker & $90(18.2)$ & 77 (15.6) & 68 (13.7) \\
\hline Target dose & $12(2.4)$ & $17(3.4)$ & $8(1.6)$ \\
\hline MRA & $297(60.1)$ & $253(51.2)$ & $253(51.2)$ \\
\hline Digoxin & 357 (72.3) & $220(44.6)$ & $41(8.3)$ \\
\hline Calcium Inhibitor & $58(11.7)$ & 69 (13.9) & $31(6.3)$ \\
\hline Aspirin & $63(12.7)$ & $51(10.3)$ & $43(8.7)$ \\
\hline Anticoagulant & 464 (93.9) & $82(16.6)$ & 67 (13.5) \\
\hline Statin & $63(12.7)$ & 63 (12.7) & $3(0.6)$ \\
\hline Clopidogrel & 63 (12.7) & $63(12.7)$ & $3(0.6)$ \\
\hline Dobutamine & $43(8.7)$ & & \\
\hline Isosorbide Dinitrate & 58 (11.7) & $36(7.3)$ & $13(2.6)$ \\
\hline Amiodaron & $98(19.8)$ & 115 (23.3) & $112(22.6)$ \\
\hline
\end{tabular}

ACEI: Angiotensin-Converting Enzyme Inhibitor; ARB: Angiotensin Receptor Blocker; MRA: Mineralocorticoid Receptor Antogonist.

more necessary to maintain effectiveness for improving patient comfort or quality of life.

Beta-blockers were under-prescribed at hospital discharge, in ICA's context working. Beta-blochers use is not common. It had not yet been initiated in the beginning of the last decade [14]. Other drugs were prescribed as digoxin. The results of this study show that the strong prescription of digoxin could be related to the underprescription of beta-blockers. In fact, the digitalis glycosides still have a salient place in heart failure management in ICA where most patients are diagnosed at NYHA class III-IV. Studies revealed that digoxin reduces the number of hospital readmission, by improving significantly symptoms particularly among patients with atrial fibrillation [7], but it had no effect on survival [7] [15] [16]. However, the effectiveness of beta-blockers has been demonstrated in heart failure in certain conditions [7] [17]. A part from contraindications and intolerance feared by physicians, beta-blockers could be indicated in case of reduced LVEF $\leq 40 \%$. They improve ventricular function, reduce hospitalization and increase survival [7] [18]. Meta-analysis and other studies suggest that beta-blockers are safe and well tolerated for patients with chronic heart failure and that the mortality benefit and other clinically relevant effects [18] [19]. The achievement of optimal dose was negligible of about 3.4\%. Patients who had reached the target doses had blood pressure that allowed them and they received beta-blockers at antihypertensive dose. Ambulatory follow up in order to increase doses of beta-blockers, is necessary especially for heart failure patients with reduced LVEF [8].

Mineralocorticoids Receptor Antagonists (MRA) were frequently prescribed at the hospitalization discharge. But this prescription was rather systematic due to congestive state and not in accordance with the ESC Guidelines. MRAs might be used on patients of NYHA class III and IV with LVEF $<35 \%$ despite their treatment with ACEI or ARB and beta-blockers or in case of intolerance to ACEI or ARB and in absence of hyperkalemia and kidney failure [7]. The clinical benefits of MRAs are: reducing of mortality and hospitalization, antifibrotic effect and reverse remodeling [20]. According to the Guidelines, there might be reserved in necessity cases.

Isosorbide dinitrate was also used mostly in hospital. Few patients (7.3\%) left hospital with this prescription. Despite the effectiveness of isosorbide dinitrate that was demonstrated in heart failure in African American patients with a preserved or reduced LVEF, it remains under prescribed [21]. Isosorbide dinitrate is more indicated 
in lung acute edema [7] [22]. That is in conformity with data of this study. Other drugs such as Aspirin, Clopidogrel and statin were prescribed for ischemic heart diseases and anticoagulants for auricular fibrillation, auricular flutter or presence of spontaneous contrast or cardiac intra-cavitary thrombus.

\section{Conclusions}

This current study has shown that, our practices of prescription are adapted to updated recommendations. Although the beta-blockers remain underprescribed because physicians have been fearing its early contraindication related to bradycardia, we noted that beta-blockers are allowed in our practice at ICA, in the management of heart failure patients. This management associates diuretic, IEC or ARB and beta-blocker according to the recommendations of ESC. However, some deficiencies may be corrected by sensitizing and educating. The optimization of the treatments after hospitalization discharge in order to improve the use of drugs recommended particularly beta-blockers by promoting program of titration might be necessary.

Finally complementary studies especially prospective 6 months or 1-year survival should enable to assess effectiveness of such approach.

\section{Conflict of Interest}

There is no conflict of interest.

\section{Acknowledgements}

The authors thank Mr Kahan Pierre of English department of UFR-SMA and Mr Gondo Vincent, administrator of the language laboratory of the Statistics and Applied Economics Institut of Abidjan for their grateful help.

\section{References}

[1] Adams Jr., K.F., Fonarow, G.C., Emerman, C.L., et al. (2005) Characteristics and Outcomes of Patients Hospitalized for Heart Failure in the United States: Rationale, Design and Primary Observations from the First 100.000 cas in the Acute Decompensated Heart Failure National Registry (ADHERE). American Heart Journal, 149, 209-216. http://dx.doi.org/10.1016/j.ahj.2004.08.005

[2] Nieminen, M.S., Brutsaert, D., Dickstein, K., et al. (2006) Euro Heart Survey Investigators Heart Failure Association. European Society for Cardiology. Euro Heart Failure Survey II (EHFS II): A Survey on Hospitalized Acute Heart Failure Patients Description of Population. European Heart Journal, 27, 2725-2736. http://dx.doi.org/10.1093/eurheartj/ehl193

[3] Stewart, S., Wilkinson, D., Hansen, C., et al. (2008) Predominance of Heart Failure in the Heart Soweto Study Cohort: Emerging Challenges for Urban Communities. Circulation, 118, 2360-2367.

http://dx.doi.org/10.1161/CIRCULATIONAHA.108.786244

[4] Damasceno, A., Mayosi, B.M., Sani, M., et al. (2012) The Causes, Treatment and Outcome of Acute Heart Failure in 1006 Patients Africans from 9 Countries: Results of the Sub-Saharan African Survey of Heart Failure. Arch Internal Med, 172, 1386-1394. http://dx.doi.org/10.1001/archinternmed.2012.3310

[5] Rodeheffer, R.J. (2003) The New Epidemiology of Heart Failure. Current Cardiology Reports, 5, 181-186. http://dx.doi.org/10.1007/s11886-003-0046-8

[6] Sliwa, K., Davison, B.A., Mayosi, B.M., et al. (2013) Readmission and Death after an Acute Heart Failure Event: Predictors and Outcomes in Sub-Sahara Africa: Results from the THESUS-HF Registry. European Heart Journal, 34, 3151-3159. http://dx.doi.org/10.1093/eurheartj/eht393

[7] McMurray, J.J., Adamopoulos, S., Anker, S.D., et al. (2012) ESC Guidelines for the Diagnostic and Treatment of Acute and Chronic Heart Failure 2012. European Heart Journal, 33, 1787-1847.

[8] Cohen-Solal, A., Leurs, I., Assyag, P., et al. (2012) Optimization of Heart Failure Medical Treatment after Hospital Discharge According to Left Ventricular Ejection Fraction: The FUTURE Survey. Archives of Cardiovascular Diseases, 105, 355-365. http://dx.doi.org/10.1016/j.acvd.2012.04.003

[9] De Groote, P., Isnard, R., Assyag, P., et al. (2007) Is the Gap between Guidelines and Clinical Practice in Heart Failure Treatment Being Filled? Insights from the IMPACT RECO Survey. European Journal of Heart Failure, 9, 1205-1211. http://dx.doi.org/10.1016/j.ejheart.2007.09.008

[10] Metra, M., Cotter, G., Gheorghiade, M., et al. (2012) The Role of Kidney in Heart Failure. European Heart Journal, 33, 2135-2143. http://dx.doi.org/10.1093/eurheartj/ehs205 
[11] Peperstraete, B. (2013) Management of Comorbidity of Heart Failure. Revue Medicale Bruxelles, 154-162.

[12] Butler, J., Arbogast, P.G., Daugherty, J., et al. (2004) Outpatient Utilization of Angiotensine-Converting Enzyme Inhibitors among Heart Failure Patients after Hospital Discharge. Journal of the American College of Cardiology, 43, 2036- 2043.

[13] Heran, B.S., Musini, V.M., Bassett, K., et al. (2012) Angiotensin Receptor Blockers for Heart Failure. Cochrane Database of Systematic Reviews, 4, CD003040. http://dx.doi.org/10.1002/14651858.CD003040.pub2

[14] Coulibaly, I., Anzouan-Kacou, J.B., Bonny, O.M., et al. (2003) Drug Treatment of Heart Failure in a Cardiological African Black Context. Medecine d'Afrique noire, 50, 513-516.

[15] The Digitalis Investigation Group (1997) The Effect of Digoxin on Mortality and Morbidity in Patients with Heart Failure. The New England Journal of Medicine, 336, 525-533. http://dx.doi.org/10.1056/NEJM199702203360801

[16] Ahmed, A., Bourge, R.C., Fonarow, G.C., et al. (2014) Digoxin Use and Lower 30-Day All-Cause Readmission for Medicare Beneficiaries Hospitalized for Heart Failure. The American Journal of Medicine, 127, 61-70. http://dx.doi.org/10.1001/jama.2014.15241

[17] Bangaloe, S., Parkar, S. and Messerli, F.H. (2006) How Useful ß-Blockers in Cardiovascular Disease? Anadolu Kardiyal Derg, 6, 358-363.

[18] Lund, L.H., Benson, L., Dahlström, U., Edner, M. and Friberg, L. (2014) Association between Use of $\beta$-Blockers and Outcomes in Patients with Heart Failure and Preserved Ejection Fraction. JAMA, 312, 2008-2018. http://dx.doi.org/10.1001/jama.2014.15241

[19] Chatterjee, S., Biondi-Zoccai, G., Abbate, A., et al. (2013) Benefits of $\beta$ Blockers in Patients with Heart Failure and Reduced Ejection Fraction: Network Meta-Analysis. BMJ, 346, f55 http://dx.doi.org/10.1136/bmj.f55

[20] Zannad, F., GattisStough, W., Rossignol, P., et al. (2012) Mineralocorticoid Receptor Antagonists for Heart Failure with Reduced Ejection Fraction: Integrating Evidence into Clinical Practice. European Heart Journal, 33, 2782-2795. http://dx.doi.org/10.1093/eurheartj/ehs257

[21] Golwala, H.B., Thadani, U., Liang, L., et al. (2013) Use of Hydralazine-Isosorbide Dinitrate Combination in African American and Other Race/Ethnic Group Patients With Heart Failure and Reduced Left Ventricular Fraction. Journal of the American Heart Association, 2, e000214.

[22] Parisis, J.T., Nikolaou, M., Mebaaza, A., et al. (2010) Acute Pulmonary Oedema: Clinical Characteristics, Prognosis Factors, and In-Hospital Management. European Journal of Heart Failure, 12, 1193-1202. http://dx.doi.org/10.1093/eurjhf/hfq138 